\title{
Nanoimprint Lithography: Toward Functional Photonic Crystals
}

\author{
Paola Lova and Cesare Soci
}

\begin{abstract}
In this chapter we review the use of nanoimprint lithography and its derivative soft-lithography techniques for the fabrication of functional photonic crystals. Nanoimprint is a viable, scalable, and cost-effective solution for large area patterning. While initially it relied primarily on pattern transfer from a rigid mold to a thermally softened polymer by embossing, in the last two decades the process evolved rapidly, giving rise to new technologies that allow direct imprint of functional materials such as conjugated polymers, metals, biological matter, and metal oxides. These advancements generated increasing interest in the use of nanoimprint lithography for the fabrication of photonic structures for light management in optoelectronic devices. After describing standard nanoimprint lithography and its derivative soft-lithography methods, we briefly discuss nanoimprint capabilities and prospects in photonic applications. In particular we review recent implementations of imprinted photonic structures for light management in organic light emitting diodes, solar cells, solid state lasers and sensors.
\end{abstract}

Keywords Nanoimprint lithography • Soft-lithography • Photonic crystals $\bullet$ Light management

\section{Introduction}

Photonic crystals are widely used in optoelectronic applications to control light propagation in light emitting diodes [1, 2], as anti-reflecting coatings, diffraction gratings and back reflectors in solar cells [3-5], resonators in lasers [6, 7], and active materials in sensors [8-10]. Notwithstanding many top-down and bottom-up

\footnotetext{
P. Lova $(\bowtie)$

Energy Research Institute at NTU (Eri@n) and Interdisciplinary Graduate School, Nanyang Technological University, 21 Nanyang link \#03-25, Singapore 637371, Singapore

e-mail: paola001@e.ntu.edu.sg

C. Soci $(\bowtie)$

Division of Physics and Applied Physics, Centre for Disruptive Photonic Technologies (CDPT) and School of Physical and Mathematical Sciences, Nanyang Technological University, 21 Nanyang link \#03-03, Singapore 637371, Singapore

e-mail: csoci@ntu.edu.sg
} 
fabrication techniques are available [11, 12], concurrent high resolution, low cost, and fast production yield over large areas are hardly achievable with standard lithographic methods. Indeed, bottom-up fabrication methods allow low cost and large area patterning, but high resolution and reproducibility are challenging. On the other hand, top-down technologies yield high resolution and reproducibility, but large area patterning requires large processing time and cost.

In the 1990s, S.Y. Chou developed a new technology, namely nanoimprint lithography (NIL), which allows overcoming these issues [13]. NIL is an embossing tool that relies on the mechanical deformation of a softened resist. Indeed, unlike optical lithography, NIL resolution is not restricted by wave diffraction, scattering, and interference $[14,15]$. Moreover, when compared to high-resolution lithography such as electron-beam and extreme ultraviolet lithography, NIL allows patterning large-area nanostructures with lower cost and higher production rate [16].

In the last 20 years, NIL has advanced considerably, overcoming early issues related to resolution [17-19], mold-substrate alignment and overlay [20-23], and polymer flow within the mold features [24-26]. Thanks to these improvements NIL is now widely employed in industrial-scale manufacturing of photonics and microelectronics devices, and it is being considered by the International Technology Roadmap for Semiconductors as a next generation patterning method for manufacturing semiconductor integrated circuits. Commercial NIL systems are available from EV Group [27], Molecular Imprints [28], Nanonex [29], Obducat [30], Smart Equipment Technology [31], NLT [32], and Suss Microtec [33].

In this chapter we will first describe the standard nanoimprint lithography techniques, as well as new "soft lithography" processes that are widely used for the fabrication of functional architectures. We will then review the recent literature on the use of imprinted photonic structures, focusing on the fabrication of active materials for organic light emitting diodes (OLED), organic photovoltaic (OPV) devices, lasers, and sensors.

\section{Basic NIL Processes}

The basic idea underlying NIL is the replication of features of a patterned mold by embossing monomeric or polymeric resists curable by thermal treatment or ultraviolet exposure. In standard NIL, a thin layer of resist is spun-cast on a substrate and heated above its glass transition temperature $\left(T_{\mathrm{g}}\right)$. A prepatterned mold is brought into contact with the coated substrate and pressed on the thermally softened polymer. The polymer resist flows within the mold features and allows pattern transfer. After cooling the mold and the rigid resist are finally separated, revealing the pattern on the latter (Fig. 1a) [13].

Thermal or ultraviolet exposure is used to modify the physical characteristics of polymers or polymer precursor resists during the imprinting process: embossing requires a low viscosity resist to allow deformation, while demolding without affecting the pattern requires high resist mechanical strength, which is acquired 
(a) T-NIL

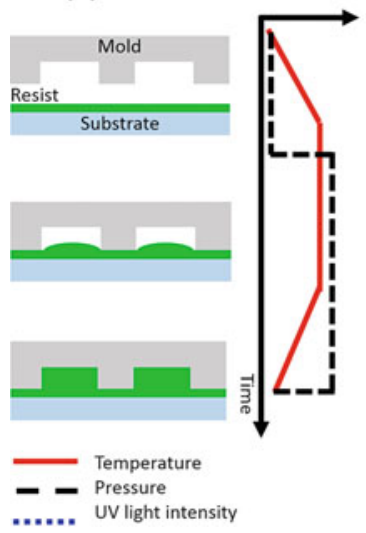

(b) UV-NIL

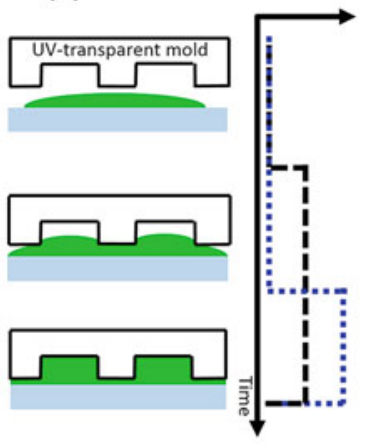

(c) STU-NIL

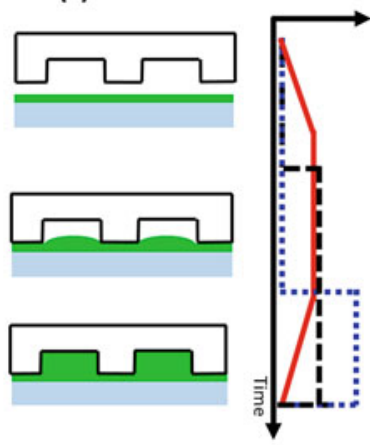

Fig. 1 Thermal (a), ultraviolet (b), and simultaneous thermal-UV (c) NIL processes. The plots display temperature (red continuous line), pressure (black dashed line), and ultraviolet light intensity (blue dotted line) profiles used during the imprinting steps

upon curing [34]. The most common thermoplastic polymers are poly(methyl methacrylate) (PMMA), polycarbonate (PC), polystyrene (PS), polyethylene $(\mathrm{PE})$, polypropylene (PP), polyethylene terephthalate (PET), and siloxane copolymers [15]. These materials cannot be re-molten after curing and are relatively easy to demold. Conversely, methacrylates and epoxides precursors are the most commonly used UV-curable resists. They are hardened during the UV exposure by photo-initiated polymerization [35]. In addition to conventional resists, NIL can also be used for direct imprinting of active and functional materials such as biological materials [36], sol-gel precursors of semiconductor oxides [37], quantum dots [38], metals [39-41], conjugated polymers [42-44], and block copolymers [45].

The imprinting of common thermoplastic resists requires high pressure and hard molds with high hardness, compression and tensile strength, as well as low thermal expansion coefficient and good corrosion resistance to ensure resist deformation and long lifetime. These molds are typically made of metals (e.g., nickel), glasses (e.g., soda-lime and fused silica), crystals (e.g., Si, sapphire, and quartz), or ceramics (e.g., $\mathrm{Si}_{3} \mathrm{~N}_{4}, \mathrm{SiC}$, and anodized aluminum oxide) [35, 46] and are fabricated by either top-down lithographic techniques [14, 47] or bottom-up methods such as self-assembly [48] followed by etching and/or metal deposition [49]. On the other hand, the imprinting of low viscous UV-curable resists can be performed with soft polymer molds that allow conformal contact with non-flat and large surfaces. Soft polymer molds have large Young module, global flexibility, and local rigidity: the global flexibility enables uniform contact to large-area substrates, even on uneven surfaces, while the local rigidity minimizes deformation of small imprinted features [50]. Soft molds are usually made by polydimethylsiloxane (PDMS), polyvinyl alcohol (PVA), polyvinyl chloride (PVC), or PMMA [51-53] and are fabricated by replication of a hard mold by NIL itself [49]. 
The main challenge of NIL is arguably the mold release, due to the high adhesion forces between the stamp and the resist which can damage the imprinted pattern during demolding. To reduce the entity of these forces, anti-sticking molecular monolayers, polymers, metal film or nanoparticles are usually deposited on the mold surface [35].

There are three standard nanoimprinting processes:

Thermal NIL (T-NIL), which imprints thermally softened polymers with rigid molds at relatively high pressure. The thermoplastic polymer is heated above its $T_{\mathrm{g}}$. Once the resist is softened, the mold is brought into conformal contact with the sample substrate and pressed onto it. Figure 1a displays the process steps together with temperature and pressure profiles adopted during the imprint.

Ultraviolet NIL (UV-NIL) is used to imprint fluid UV-curable resists. The low viscosity typical of these resists allows room temperature imprinting and relatively low pressure. The resist, which is a polymer precursor, is hardened in situ by UV-irradiation through the transparent mold (Fig. 1b).

Simultaneous Thermal-UV NIL (STU-NIL) is used to imprint pre-polymerized resists with hard or soft molds. These resists yield good substrate coverage and lower imprinting temperature with respect to T-NIL so that issues related to thermal expansion and polymers shrinkage are minimized (Fig. 1c).

After demolding, the patterned resist can be dry etched to remove the residual polymer layer or to transfer the pattern to the substrate.

\section{Advanced NIL Techniques}

The need for fast and low cost fabrication of functional and active materials structures without affecting their optical and semiconducting properties has led to the development of new nanoimprint methods. In particular, advanced NIL and soft-lithography techniques are commonly used for large-scale fabrication of functional photonic crystals.

Roller NIL: Roller-NIL (i.e., roll-to-roll NIL, R2R-NIL, and roll-to-plate NIL, R2P-NIL) was developed by Chou et al. in the late 1990s to achieve high imprinting throughput and large area patterning [54]. In R2R-NIL, a series of rollers coat a moving substrate belt with a resist. Another roller imprints the belt, which is then exposed to UV light to cure the resist (Fig. 2a). R2P-NIL is a variation of this process. Here a substrate covered with the resist is flattened onto a rigid plate which is moved below a roller mold (Fig. 2b) $[55,56]$. Roller molds are fabricated by direct patterning of metal cylinders or wrapping flexible molds on the rollers [57-59].

Roller-NIL can reach fabrication speed of $\sim 1 \mathrm{~m} / \mathrm{min}\left(10^{4}-10^{5}\right.$ times faster than traditional electron beam lithography) and is currently used in semi-industrial production (see Sects. 4.1 and 4.4) [55]. 

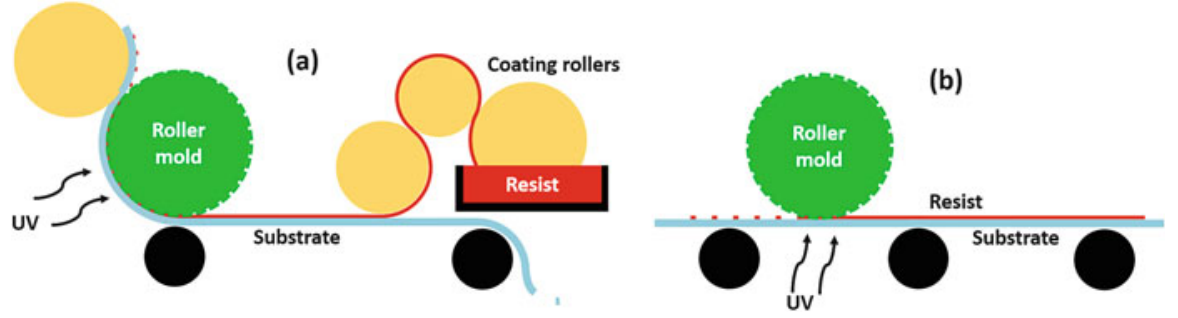

Fig. 2 (a) Roll-to-roll and (b) roll-to-plate NIL process schemes
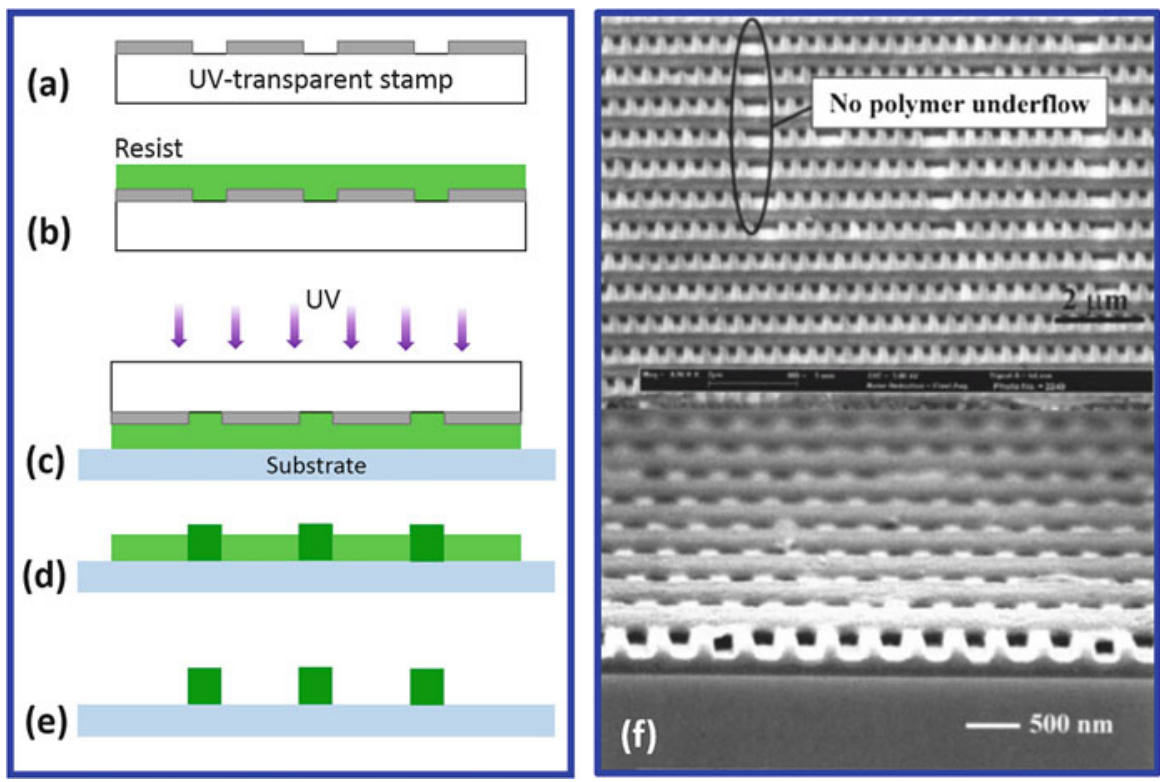

Fig. 3 Reverse UV-NIL process: A metal patterned UV-transparent mold (a) is first spun-cast with a resist (b) then pressed onto the substrate and exposed to UV light (c). The stamp is removed (d) and the uncured resist is wet etched to reveal the pattern (e). (f) Scanning electron microscope (SEM) micrograph of 3D structures fabricated by multiple reverse UV-NIL (Reprinted with permission from [64]. Copyright 2006, American Vacuum Society)

Reverse NIL (R-NIL): In R-NIL, a resist is spun-cast on the mold rather than on the substrate and then transferred on the latter by the imprint process [60-62]. This technique easily allows three-dimensional structures by multiple patterning [63-65]. In the process shown in the left panel of Fig. 3, an UV-curable resist is spun-cast on a patterned metal-quartz stamp. The stamp holding the resist is then pressed onto a substrate and exposed to UV light. After demolding, the unexposed resist is rinsed away with a solvent revealing the grating [64]. Process reiterations allow the growth of patterned multilayers to form 3D structures like the one shown in Fig. 3f. 
(a)

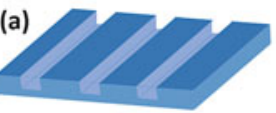

(b)

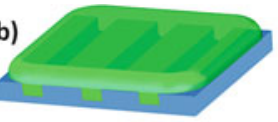

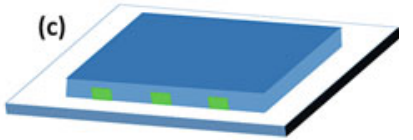

(d)

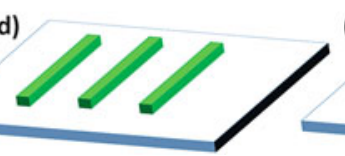

(e) (f)

(f)

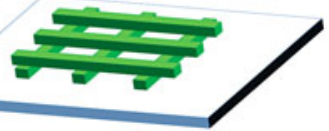

Fig. 4 Schematic of mTM process. An elastomeric mold (a) is wetted with the resist (b). The excess polymer is removed and the mold is transferred onto a substrate (c), the mold is then removed revealing the pattern (d). Repetition of the process (e) allows 3D structures (f)

(a)

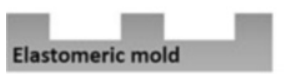

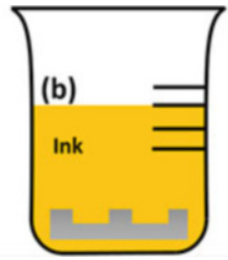

(c)

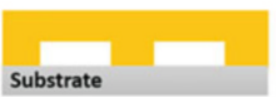

(d)

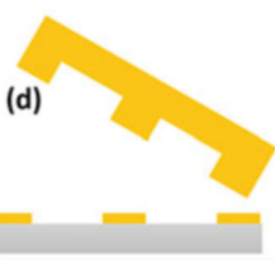

Fig. 5 An elastomeric mold (a) is inked with the material to imprint (b) and pressed on a substrate (c) to release the ink revealing the imprinted pattern (d)

Microtransfer molding (mTM): Microtransfer molding is a variation of reverse NIL. In this technique the features of an elastomeric mold are filled with a UV-curable polymer precursor. The excess polymer is removed from the surface using a blading slab. The mold is then pressed onto a surface and cured [66]. Reiterations of the process allow to create 3D structures. The process schematic is shown in Fig. 4.

Microcontact printing $(\mu C P): \mu \mathrm{CP}$ relies on the property of alkanethiols to form self-assembled monolayers on gold surface [67]. In this technique an elastomeric mold (e.g., silicone, poly (urethane acrylate) (PUA) or PDMS) is inked with an alkanethiol and then pressed on a gold film to transfer the thiol pattern (Fig. 5). Printed alkanethiols are stable enough to be used as etching masks [67]. Examples of the application of $\mu \mathrm{CP}$ are given in Sects. 4.1 and 4.4.

In recent years, $\mu \mathrm{CP}$ was modified to increase pattern homogeneity and to imprint functional materials such as polymers [68], metals [69], nanoparticles [70], proteins [71], lipids [72], and DNA [73] on inorganic and polymer substrates [68]. Among new techniques, Supramolecolar Contact Printing uses $\mu \mathrm{CP}$ to immobilize receptor molecules able to selectively physisorb enzymes, proteins, and cells. Dip Pen Nanolithography exploits atomic force microscope tips inked with receptor molecules to pattern biological material. Polymer Pen Imprinting uses an array of inked polymer tips typically made by PDMS which are brought into contact with the surface to imprint and moved with a piezoelectric system [74]. Another variation of $\mu \mathrm{CP}$, namely Lift-up, consists in the deposition of an active material on the 


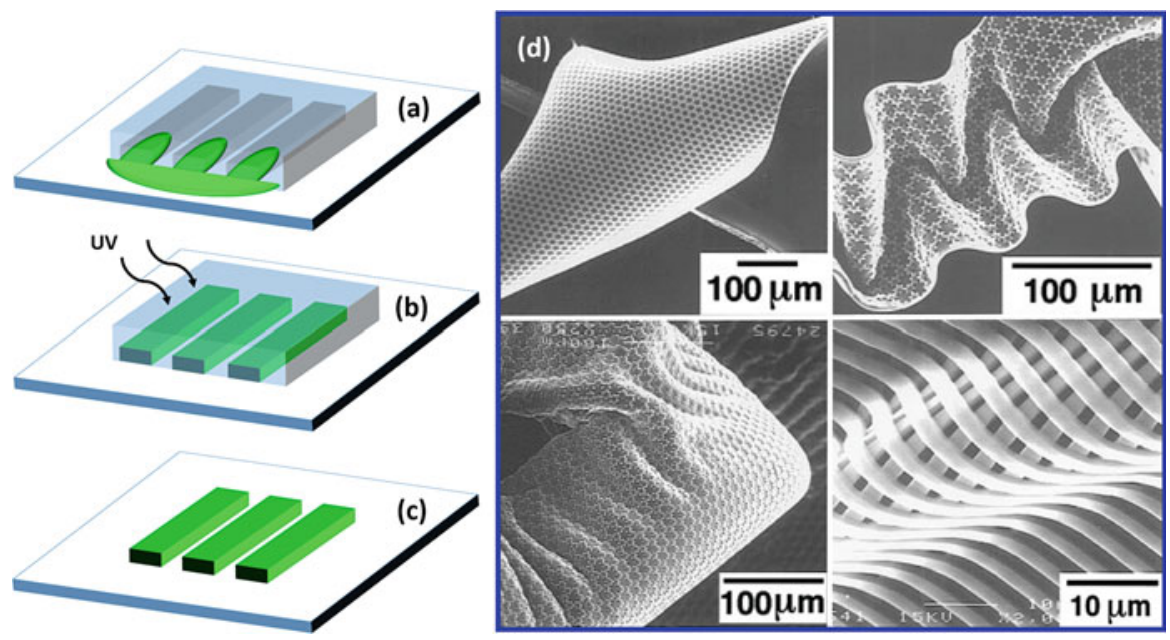

Fig. 6 (a)-(c) MIMIC process schematics, (d) SEM micrograph on resulting free-standing polymer patters (Adapted with permission from [79]. Copyright 1996 American Chemical Society)

substrate on which a soft mold is pressed. The resist in contact with the mold features sticks to it and is removed during the demolding to reveal the pattern [75, 76]. Finally, in Magnetic Field Assisted $\mu C P$ a PDMS layer containing magnetic iron nanoparticles is deposited on the top of the standard PDMS mold and placed into a magnetic field to control the stamp pressure on the substrate during the imprinting. This technique yields high pattern uniformity and homogeneity.

Micromolding in capillaries (MIMIC): In MIMIC an elastomeric mold is placed on a substrate and put in contact with some drop of fluid pre-polymer, polymer solution, or thermally softened polymer (Fig. 6a). The liquid fills the network channels by capillary action and is subsequently cured (Fig. 6b) [77, 78]. MIMIC can yield free-standing film patterns by two procedures. In the first a pattern is formed on a support, which is then etched until complete dissolution. In the second, the pattern in formed between two elastomeric molds, which are then peeled from the free-standing pattern [77]. Free-standing structures resulting from these processes are displayed in Fig. 6d.

Solvent Assisted Micromolding (SAMIM): In SAMIM a good solvent of the resist is applied on the mold surface. As the polymer contacts the wetted mold, a thin layer swells and conforms to the mold pattern [80]. Solvent diffusion and evaporation cause resist solidification. An example of SAMIM is reported in Sect. 4.3.

A recent variation of this process consists in the swelling of the polymer resist with solvent vapors. This method, named Solvent Vapor Assisted Imprint Lithography (SVAIL), was developed to reduce imprinting pressure and temperature 
which are detrimental for many photoactive polymers and avoid residual polymer layers which require further etching steps [81].

\section{Applications}

Nanoimprint and its derivative lithographies not only allow low cost, fast production, and large-scale nanofabrication, but also enable capabilities that would be unconceivable otherwise. For instance, it is possible to directly imprint a wide variety of active materials such as photoactive conjugated polymers, gain molecules, metals, and metal oxides without affecting their optical and conductive properties. This remarkable capability has been widely exploited for the production of photonic patterns for light extraction enhancement in OLED, light management in organic solar cell, resonators for organic solid state lasers, and molecular sensors. In the following we review recent results on the fabrication of photonic structures for various device components, such as substrates, active layers and electrodes, and their effect on the device performance.

\subsection{Organic Solar Cells}

Photoactive conjugated polymers have high extinction coefficient that allow thin film devices processable by roll-to-roll printing [82, 83]. However, their low charge carrier mobility and high recombination rate limit the efficiency of organic photovoltaic devices (see 13th chapter). Thus, roll-to-roll compatible methods for efficiency enhancement are highly researched. In the last decade, NIL became a preferred tool for the fabrication of photonic structures aimed to enhance photovoltaic device performance. PhC have demonstrated absorption enhancement by light diffraction, wave guiding within the photoactive layer, or coupled wave guiding and plasmonic effects achieved structuring the metal electrodes $[84,85]$. Recent literature on the imprinting of photonic crystal for light management of the different solar device components is reviewed in the following.

The simplest organic solar cell consists in a film of organic photoactive material sandwiched between two electrodes. A buffer layer can be inserted between the active material and the anode to block electron diffusion toward the latter. From top to bottom, the device structure consists of:

- Glass or polymer substrate;

- Semitransparent anode for positive charges collection, usually made of transparent conducting oxides (e.g., indium tin oxide, ITO);

- Hole injection layer aimed to block electron diffusion to the anode. The most used buffer layer is poly(3,4-ethylenedioxythiophene):polystyrene sulfonate (PEDOT:PSS). At times, it can also double as negative electrode; 
- Photoactive material, which consists in an electron donor (i.e., a conjugated polymer) and an electron acceptor (usually a fullerene derivate) layered or blended in a bulk heterojunction (BHJ);

- A metal cathode for negative charge collection.

The following results were achieved by nanoimprinting one of these cell components:

Substrate: The imprinting of periodic 1D and 2D structure in the device substrate aims to diffract light and increase its path within the photoactive layer. Substrate imprinting is the simplest approach to integrate PhCs in organic solar cells. Indeed, commercial UV- and T-NIL can be used. In this regard, 2D structures imprinted by UV-NIL on resists demonstrated increased light absorption [86-88] and device efficiency up to $42 \%$ higher than flat devices [87].

Electrodes: Metal sub-micrometric structures can increase light absorption thanks to light diffraction from the dielectric lattice and surface plasmonic resonance excitation [89-91]. Gold and silver electrodes imprinted with 1D and 2D sub-micrometric periodical patterns have been used as transparent anodes in poly (3-hexylthiophene):phenyl-C61-butyric acid methyl ester (P3HT:PCBM) [92, 93] and copper phthalocyanine:buckminsterfullerene (CuPC:C60) [94] devices. These metal gratings were fabricated by $\mu \mathrm{CP}, \mathrm{R} 2 \mathrm{R}-\mathrm{NIL}$ [92] (Fig. 7a) and T-NIL associated with metal evaporation $[95,96]$ on both hard and flexible substrates. The imprinted devices demonstrated $4.4 \%$ maximum power conversion efficiency with enhancement of $\sim 52 \%$ compared to standard ITO electrodes (Table 1).

Hole Injection layer (PEDOT:PSS): Imprinted periodical patterns on the charge injection layer provide two benefits. First, the interface with the photoactive material is increased and charge separation is enhanced. Second, light diffraction and wave guiding increase the light path within the active layer. Nanoimprinting of PEDOT:PSS can indeed increase the device efficiency up to $90 \%$ compared to flat devices [97], but because of its sensitivity to high pressure and temperature [98, 99], soft mold (e.g., PDMS [97, 100, 101] and PUA [102]), and low temperature and pressure processes must be employed (Table 1). Only recently Yang et al. showed that T-NIL of PEDOT:PSS with hard mold can achieve $15 \%$ efficiency enhancement in spite of thermal degradation when the polymer is dehydrated in dry environment for $24 \mathrm{~h}$ [103].

Photoactive layer: Active layers are imprinted to achieve three different goals: First, to introduce periodic structure thus light diffraction and/or guided modes in the photoactive layer. Second, to increase the heterointerface between donor and acceptor materials in bilayer geometries. Third, to orientate polymer chains and boost carrier mobility in the donor material.

In bulk heterojunction, the interface between donor and acceptor materials is maximized. On the other hand, phase segregation and low absorption of thin photoactive films limit the efficiency. Since thickening the active layer increases resistance due to high recombination rate and low charge carrier mobility, the 

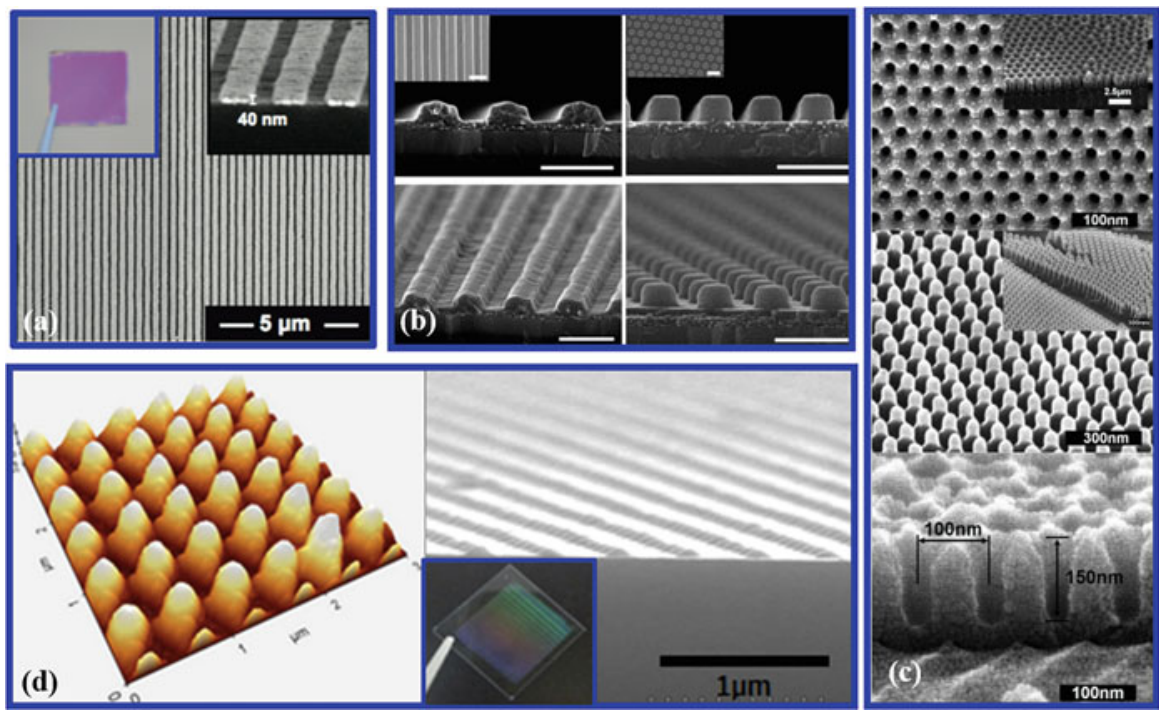

Fig. 7 (a) Scanning electron microscope image of a Au grating with period of $280 \mathrm{~nm}$ used as electrode and for photonic-plasmonic absorption enhancement. The inset shows a photograph of the grating (Adapted with permission from [95]. Copyright 2011 American Chemical Society). (b) Imprinted P3HT:PCBM 1D and 2D PhC, scale bars are $500 \mathrm{~nm}$ grating (Adapted with permission from [105]. Copyright 2011 American Chemical Society). (c) Imprinted P3HT:PCBM bulk heterojunction. grating (Adapted with permission from [117]. Copyright 2010 WILEY-VCH Verlag GmbH \& Co. KGaA, Weinheim). (d) Atomic force (left) and scanning electron (right) microscope images of a 2D pattern imprinted on PEDOT:PSS at room temperature (Adapted with permission from [102]. Copyright 2013 Elsevier)

optical thickness can be increased by imprinting periodical patterns. This approach yielded power conversion efficiency increase up to $\sim 15-30 \%$ with respect to flat devices (Table 1) [104-109].

Imprinting of active blends has some drawbacks: Tumbleston et al. showed that T-NIL of region-regular crystalline P3HT:PCBM blend leads PCBM concentration below the optimum in certain area of the device and affect the cell performances [110]. As a consequence, imprinting sub-wavelength patterns in the solely donor to increase donor-acceptor interfacial area seems a more promising strategy. Indeed, sub-wavelength gratings [111-115], nanopillars [116-118], holes [119], and dots array [120] imprinted in the donor polymers yielded efficiency increase up to $200 \%$ (with respect to a flat device with efficiency of $0.82 \%$ ) when the size of the imprinted features is comparable or less than the charge diffusion length [119, 121]. On the other hand, when the pattern periodicity is comparable with visible light wavelength, the heterointerface is reduced but light diffraction and guided modes provide larger photoactive layer absorption [122-124] overall increasing efficiency up to $560 \%$ (with respect to a flat device with efficiency of $0.17 \%$ ).

Nanoimprinting advantages are not limited to extended donor-acceptor interfacial area and improved light absorption. NIL can control chain alignment orientation 


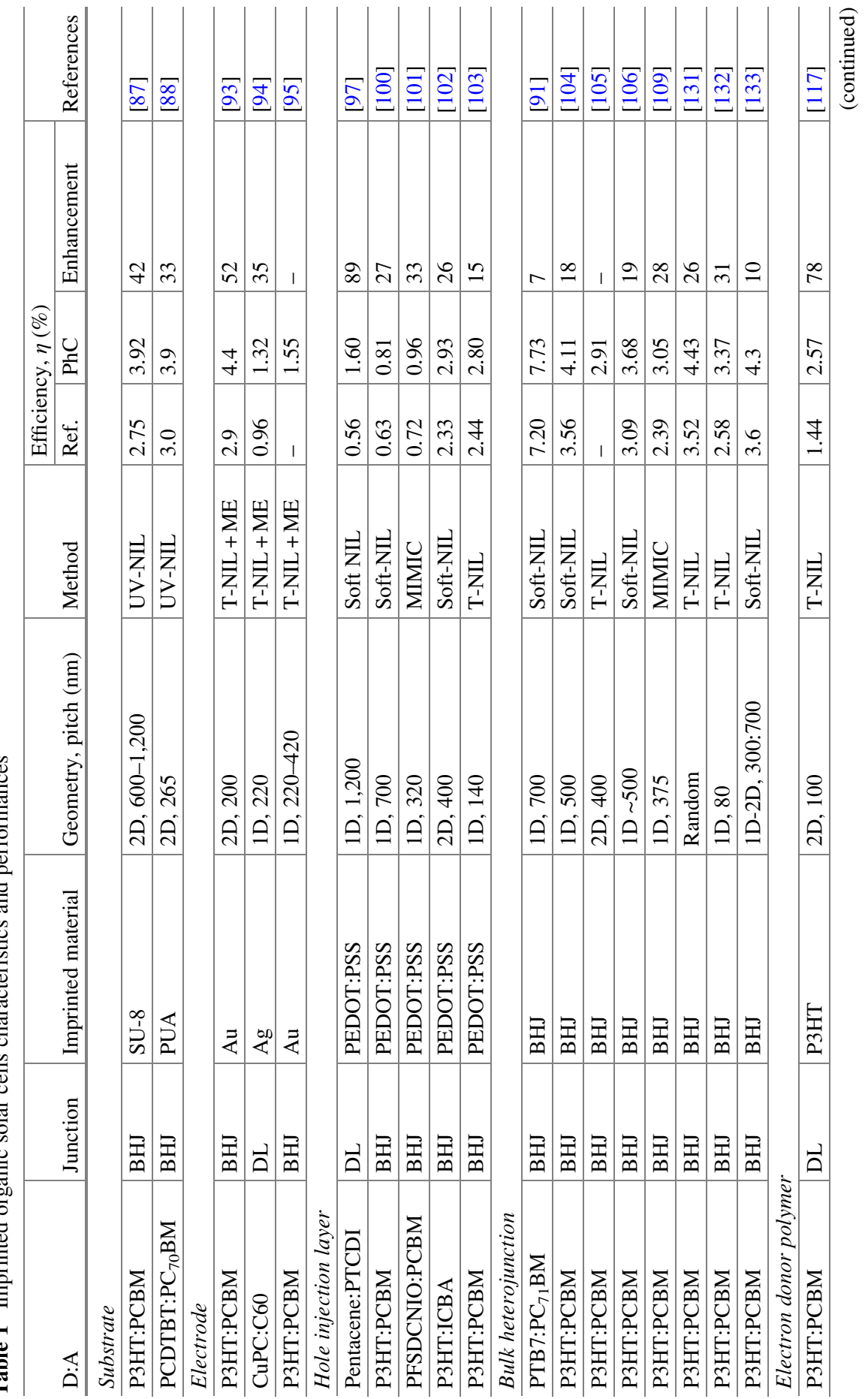




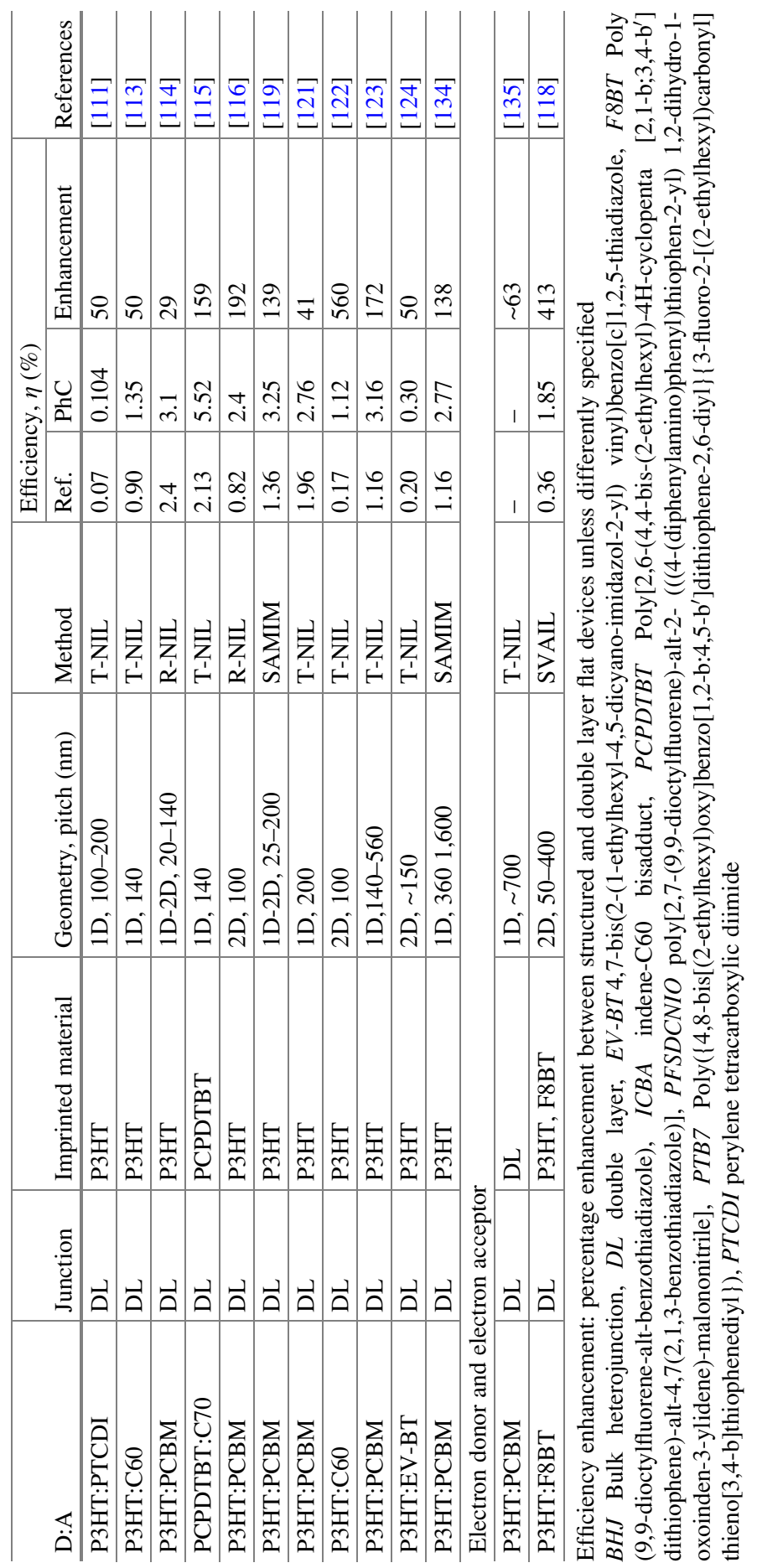


Table 2 Recent achievement in nanoimprinted OLED

\begin{tabular}{|c|c|c|c|c|c|c|c|c|}
\hline \multirow{2}{*}{$\begin{array}{l}\text { Imprinted } \\
\text { material }\end{array}$} & \multirow[b]{2}{*}{ Method } & \multirow{2}{*}{$\begin{array}{l}\text { Geometry, } \\
\text { pitch (nm) }\end{array}$} & \multicolumn{5}{|c|}{ Enhancement $^{\mathrm{a}}(\%)$} & \multirow[b]{2}{*}{ References } \\
\hline & & & EQE & $\mathrm{CE}$ & $\mathrm{L}$ & LE & $\mathrm{PE}$ & \\
\hline \multicolumn{9}{|c|}{ Substrate and top layer } \\
\hline $\begin{array}{l}\text { Hydrogen } \\
\text { silsesquioxane }\end{array}$ & $\begin{array}{l}\text { Low } \\
\text { T-NIL }\end{array}$ & $2 \mathrm{D}, 600$ & - & 17 & $\sim 160$ & - & 43 & {$[145]$} \\
\hline Glass & T-NIL & $2 \mathrm{D}, 200-300$ & - & - & 50 & - & - & {$[142]$} \\
\hline $\mathrm{PC}$ & $\begin{array}{l}\text { Double } \\
\text { T-NIL }\end{array}$ & $2 \mathrm{D}, 200-400$ & - & 180 & - & - & '- & {$[148]$} \\
\hline PDMS & $\begin{array}{l}\text { Low-T } \\
\text { NIL }\end{array}$ & $2 \mathrm{D}, 10 \times 10^{3}$ & - & - & - & $\sim 200$ & - & {$[138]$} \\
\hline UV-resist & UV-NIL & $2 \mathrm{D}, 5^{*} 10^{4}$ & - & - & - & 70 & - & {$[146]$} \\
\hline \multicolumn{9}{|l|}{ Resist } \\
\hline UV-resist & UV-NIL & $1 \mathrm{D}, 500$ & - & - & - & - & 93 & {$[144]$} \\
\hline UV-resist & UV-NIL & 2D-400 & - & 6 & 7 & & 7 & {$[137]$} \\
\hline UV-resist & R2R-NIL & $2 \mathrm{D}, 50 \times 10^{3}$ & - & - & - & 60 & - & [139] \\
\hline PMMA & UV-NIL & $2 \mathrm{D}, 2 \times 10^{5}$ & - & - & 56 & - & - & {$[140]$} \\
\hline \multicolumn{9}{|c|}{ Hole injection and active layer } \\
\hline PEDOT:PSS & $\mathrm{mTM}$ & 1D-2D, 500 & $\begin{array}{l}15- \\
25 \\
\end{array}$ & - & - & - & - & {$[155]$} \\
\hline $\begin{array}{l}\text { PEDOT:PSS } \\
+ \text { MEH-PPV }\end{array}$ & Soft-NIL & $1 \mathrm{D}, 320$ & - & 35 & - & - & - & {$[157]$} \\
\hline $\begin{array}{l}\text { PEDOT:PSS } \\
+ \text { Top layer }\end{array}$ & Soft-NIL & $2 \mathrm{D}, 250$ & 131 & & - & - & 105 & {$[158]$} \\
\hline $\begin{array}{l}\text { PEDOT:PSS } \\
+ \text { Top layer }\end{array}$ & $\begin{array}{l}\text { T-NIL } \\
+ \text { UV-NIL }\end{array}$ & $2 \mathrm{D}, 200-400$ & 134 & 90 & - & - & - & {$[156]$} \\
\hline
\end{tabular}

$C E$ current efficiency (cd/A), $L$ luminance $\left(\mathrm{cd} / \mathrm{m}^{2}\right), P E$ power efficiency $(\mathrm{Im} / \mathrm{w}), E Q E$ external quantum efficiency, LE Light extraction efficiency

${ }^{\mathrm{a}}$ Maximum enhancement compared to a flat device reference

in conjugated crystalline [122, 125, 126] and low molecular weight [127] polymers. It has been demonstrated that energetic stabilization [128], nano-confinement [129, 130], and surface interaction with the mold [42] lead to preferential chain orientation with high charge mobility, increasing the solar cell performance [123].

Table 2 summarizes the data presented so far. It is clear that the imprinting of donor-acceptor blend is the worst performing approach with power conversion efficiency enhancement below $25 \%$ with respect to the flat substrate. Slightly better performance is achieved by the imprinted substrate and hole injection layer with enhancement reaching 42 and $200 \%$, respectively. The highest power conversion efficiencies were achieved by imprinting of the solely donor or acceptor layers, which increased device efficiency by around $500 \%$. 


\subsection{Organic Light Emitting Diodes}

Although internal quantum efficiency of organic emitters can approach $100 \%$, waveguiding and total internal reflection due to high refractive indices can prevent photon extraction in OLED. To enhance device performance, 3D light propagation control can be used to forbid in-plane guided mode and to favor out-of-plane light extraction. This can easily be achieved by $2 \mathrm{D} \mathrm{PhC}$ where the stop band prohibits guided modes in the two in-plane directions, so that light can only propagate out-ofplane (see 15th chapter) [136].

The simplest approach to integrate a photonic structure in OLEDs consists in the imprinting of a resist placed on top of a device [137-140] or on the substrate where the OLED is subsequently grown [141-147]. As an example of this strategy, the left panel of Fig. 8 shows the structure of a devices fabricated on a double patterned substrate. Here T-NIL was used to imprint the two surfaces of a polycarbonate substrate to eliminate waveguiding at the active material-substrate and substrateair interfaces and to increase light extraction and propagation at high angles [148]. The double pattern improved the device current efficiency by a 2.8 factor and enhanced the flexible OLED luminance by a factor five with respect to the flat structure. The right panel of Fig. 8 shows the comparison between a flat and a patterned OLED consisting in imprinted PS pillars, where a buffer layer was
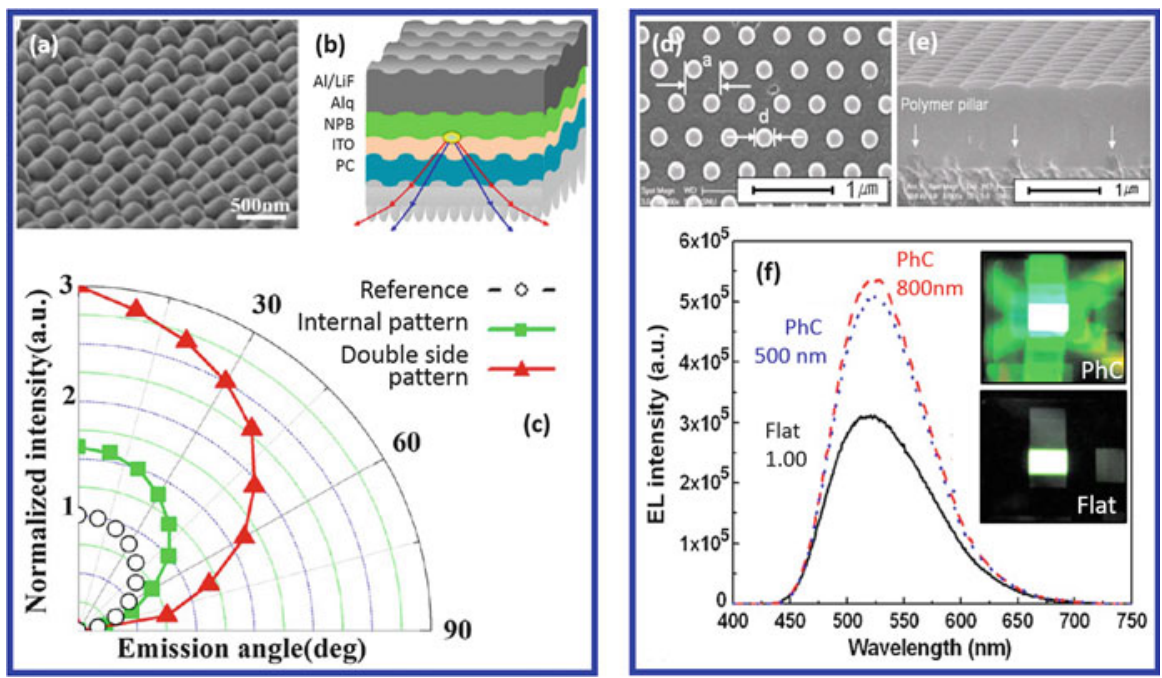

Fig. 8 Left panel: (a) thermally imprinted polymer substrate, (b) double imprinted OLED structure, and (c) angle dependence of light emission of the imprinted OLED. (Adapted with permission from [148]. Copyright 2014 American Chemical Society). Right panel: SEM micrograph of polystyrene imprinted polymer pillars (d) and cross-sectional image of the PhC buffer layer deposited on the pillar (e). (f) Electroluminescence intensity OLED with and without the PhC. (Adapted with permission from [147]. Copyright 2008 AIP Publishing LLC) 
deposited to smooth the photonic structure. The smoothed features enhanced luminescence intensity by $56 \%$ [147].

NIL capacity of direct imprinting functional materials have been widely exploited to control and enhance the spontaneous emission of organic [149, 150] and composite emitters [151-153] and to structure organic electrodes [75, 154, 155] in flexible devices. Zhou et al. showed a double imprinted white OLED made by phosphorescent emitters with a multilayer energy cascade [156]. The device was produced by direct embossing of a PEDOT:PSS layer where the OLED was then fabricated. A second embossing on a UV-curable resist, which was spun-cast on the OLED bottom surface, allowed out-coupling enhancement by a factor 2 and improvement of external quantum efficiency by $\sim 130 \%$. The same group reported the incorporation of Bragg gratings in both hole transporting (PEDOT:PSS) and emitting (poly(p-phenylene vinylene), MEH-PPV) layers by NIL, achieving $35 \%$ current efficiency enhancement with respect to the flat devices [157]. These results prove that, in addition to high throughput and low costs, NIL can greatly simplify the fabrication process to yield high efficient structure.

Table 2 summarizes recently published achievement attained integrating nanoimprinted photonic structures in OLED active materials, substrates, and top layers. The data show a general enhancement of device performance with maximum gain for devices coupled with imprinted substrates and top layers.

\subsection{Lasers}

Since optically pumped laser emission from organic molecules confined in a photonic structure was demonstrated [159], researchers focused on the development of low cost fabrication processes for dielectric lattices to reduce lasing threshold (see 11th and 17th chapters). Nanoimprint and soft-lithography are the techniques of choice to structure polymer distributed feedback and band edge lasers. So far, NIL has been adopted to imprint periodic structures for lasing in polymer and inorganic substrates, dye doped resists, and gain polymers.

In 1998, Berggren et al. reported one of the first examples of $\mathrm{PhC}$ imprinted on flexible polymer for lasing [160]. They achieved low threshold laser (Table 3) by deposition of tris(8-hydroxyquinolinato)aluminum (Alq) doped with 4-dicyanomethylene-2-methyl-6-p-dimethylaminostyryl-4H-pyran (DCM) on a Mylar ${ }^{\circledR}$ substrate where a Bragg grating was previously patterned by T-NIL. So far, lasing from gain molecules and polymers imprinted on either hard [161-164] or flexible polymer [165-167] substrates yielded lasing threshold lower than $20 \mathrm{~kW} / \mathrm{cm}^{2}$.

A simpler but effective approach to lower $\mathrm{PhC}$ laser threshold relies on the imprinting of a resist doped with the gain material. Direct imprinting reduces the fabrication process to one single step, thus decreasing material consumption as well as fabrication time and costs. As a result, standard T- and UV-NIL were applied to 


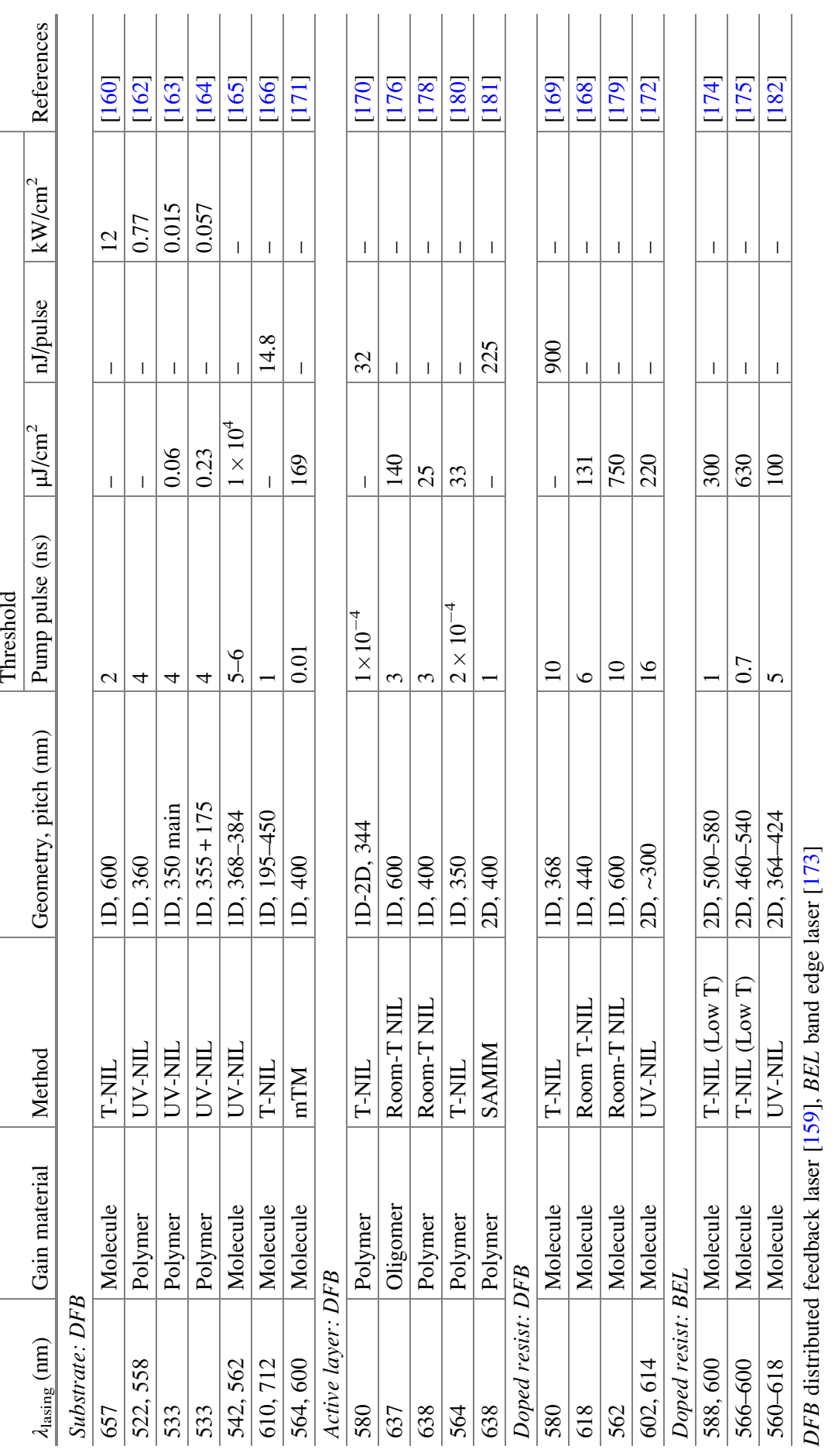



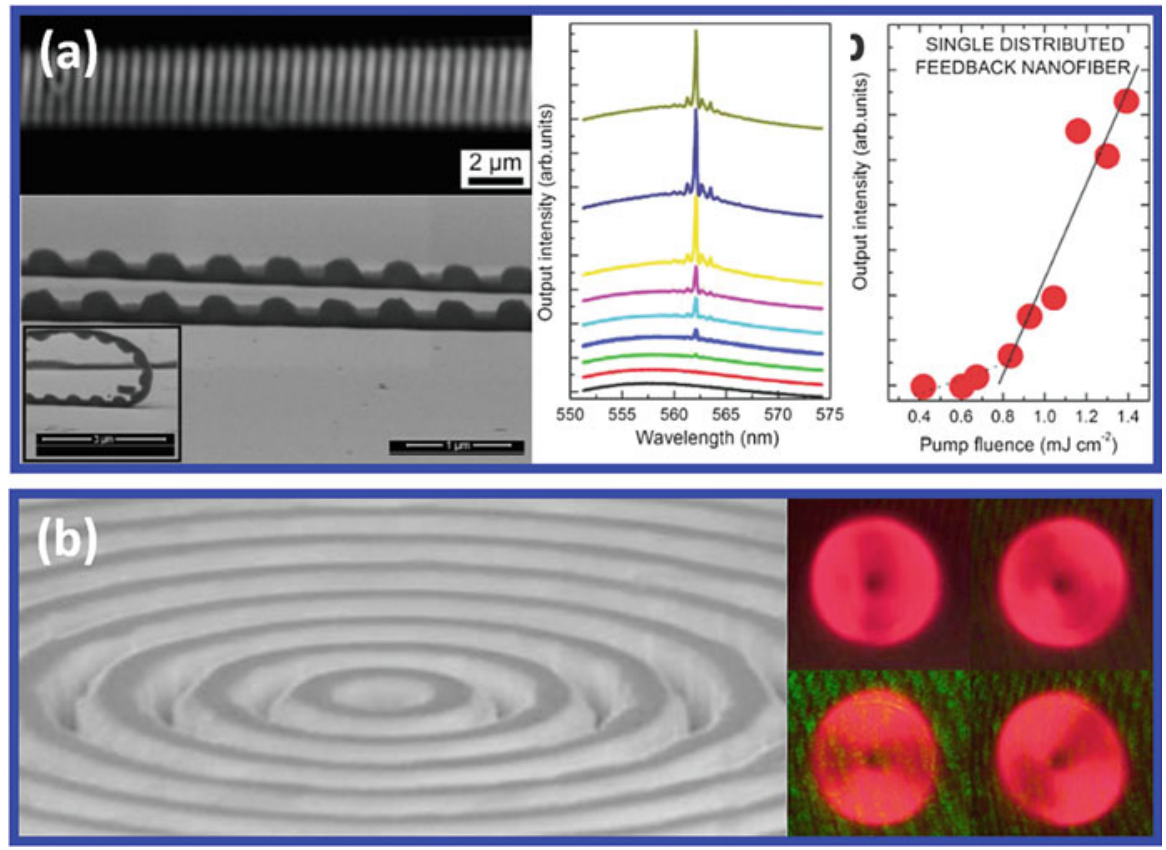

Fig. 9 (a) DFB laser fiber SEM micrograph (left) and lasing threshold (right) (Adapted with permission from [179]. Copyright 2014 WILEY-VCH Verlag GmbH \& Co. KGaA, Weinheim). (b) Circular R6G DFB laser SEM micrograph and photograph (inset) (Adapted with permission from [168]. Copyright 2007 AIP Publishing LLC)

dye doped resist to obtain low threshold distributed feedback [168-171] and band edge lasers [172-175] (Table 3).

$\mathrm{PhC}$ can also be directly imprinted into gain polymers and oligomers. To avoid degradation of optical properties, low temperature imprinting methods such as SAMIM and low temperature NIL of 1D gratings have been proposed (see Table 3). Pisignano et al. demonstrated a new direct patterning of a thiophene based oligomer achieved by prolonged hard mold pressure at room temperature, which does not require thermal nor UV curing [176]. The same group extended the new imprinting method to photoactive polymers achieving thresholds below $10 \mathrm{~kW} / \mathrm{cm}^{2}[177,178]$.

Figure 9 displays some distributed feedback (DFB) lasers [159] fabricated using different approaches: a thermally imprinted rhodamine 6G (R6G) doped PMMA laser fiber [179] and a circular DFB laser directly imprinted in MEH-PPV doped PMMA [168].

Table 3 summarizes recent advances in imprinted polymer and organic lasers. From the data we see that lower lasing threshold is reported for distributed feedback lasers where the photonic structure is imprinted on the substrate, while the highest threshold is reported for an imprinted distributed feedback laser fiber (Fig. 9a), where the feedback grating in the narrow 1D fiber does not confine light as effectively as the grating that extends over a $2 \mathrm{D}$ plane. 


\subsection{Sensing}

There is a steadily growing need for lab-on-a-chip PhC detectors that combine high resolution, sensitivity, and rapid detection in numerous applications such as healthcare, environmental monitoring, and security; however, the development of such detectors is hampered by the lack of low cost materials, fabrication processes, and reproducibility. Research is focusing its effort to the development of new low cost methods for all-plastic disposable devices. In this paragraph we summarize the advance in PhC based sensors fabricated by NIL which promise large-scale production of multi-parameter, label-free sensing platforms.

Standard PhC sensing is generally based on the variation of either effective refractive index or lattice spacing caused by molecules interaction within the crystal $[183,184]$. These structures represent the simplest $\mathrm{PhC}$ sensors and can be directly imprinted on polymers (see also 2nd and 18th chapters). In 2003 Cunningham et al. reported on a nanoimprinted $1 \mathrm{D} \mathrm{PhC}$ sensor for the imaging of bimolecular interaction. The sensor was made by a functionalized UV-imprinted epoxy resin and sputtered titanium oxide as low and high index media, respectively [185]. Later on, the same group replaced the epoxy resin with a thermally curable sol-gel silica precursor in order to increase $\mathrm{PhC}$ dielectric contrast and its sensitivity [186]. These detectors reported refractive index sensitivity (i.e., PBG spectral shift) for both bulk materials and thin layers contacted with the PhC surface. More recently, the bird flu spreading revealed the need for very fast detection of viruses by low cost disposable devices. Endo et al. responded to this demand with self-assembled copolymer imprinted to a 2D PhC on cyclo-olefin substrate and functionalized with H1N1 virus antibody. In their system, an antigen-antibody complex is formed after exposure to the virus. The complex acts as an antireflective coating and reduces PBG reflection intensity (Fig. 10). This device, with sensitivity up to $1 \mathrm{pg} / \mathrm{ml}$ antigen in human saliva, opened a new perspective in the monitoring and control of disease spreading [187]. An alternative approach aimed to disease control was provided by the pioneering work of Morhard et al. in year 2000, which reported bacterial detection by antibodies patterned by $\mu \mathrm{CP}$ [188]. Escherichia coli antibodies were directly imprinted on a rigid substrate. The selective antibody-bacteria binding gave rise to a diffraction pattern arising from the new cellular $\mathrm{PhC}$.

In the last few years, NIL was also used for the realization of $\mathrm{PhC}$ sensor based on lasing. Similar to standard $\mathrm{PhC}$ sensor, the interaction between the $\mathrm{PhC}$ laser and external molecules affects the PBG features inducing the spectral shift of the laser peak. In 2005, Rose et al. showed high sensitivity to trace of explosive vapors [189]. In their system, a gain semiconducting polymer deposited on a PDMS grating is exposed to di- and trinitrotoluene. Exposure to explosives inhibits lasing by increasing the laser threshold. DFB lasers sensitivity to environmental refractive index variation was also recently demonstrated for both polymer and silica substrates patterned by NIL [190-192]. In these devices a gain material is deposited on a grating to achieve lasing. The device is then exposed to environments with different refractive indices, which induce the spectral shift of the lasing peak. 


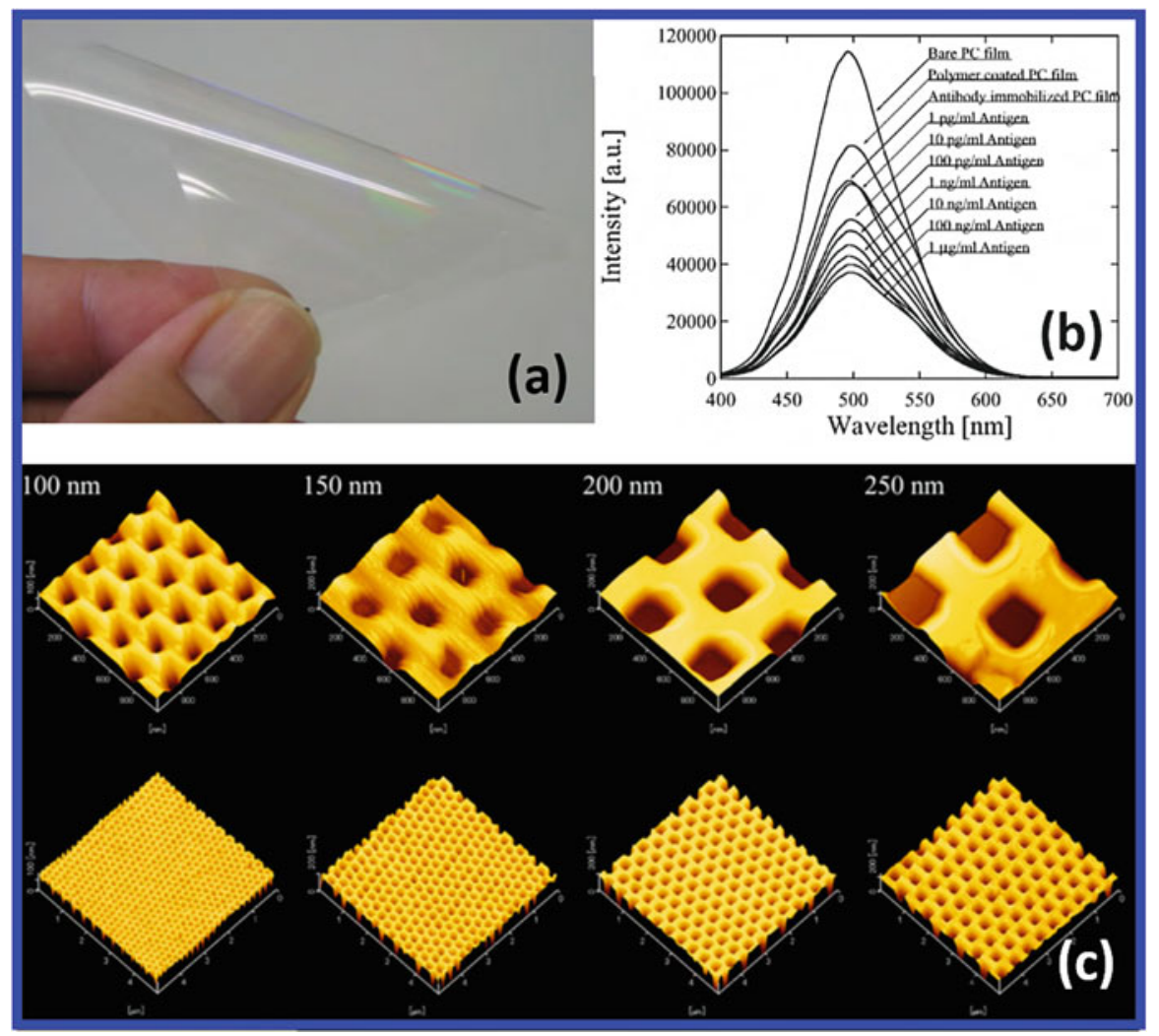

Fig. 10 (a) Photograph of Imprinted of 2D grating H1N1 sensor, (b) Reflection spectra of the sensor exposed to different H1N1 virus concentrations, and (c) atomic force microscopy micrographs of the sensor surface (Adapted with permission from [187]. Copyright 2010 Elsevier)

In 2009 Kristensen et al. reported a functionalized dye doped polymer $\mathrm{PhC}$ suitable for the detection of cervical carcinoma cells. In this sensor, the density of carcinoid cells growth on the laser itself generates linear spectral shift of the lasing peak [193]. A more sophisticated sensor geometry was recently reported by Vannhme et al., where an optically pumped DFB laser was connected to a microfluidic channel by a waveguide. The whole structure was produced by T-NIL of PMMA substrates. The imprinted geometry allowed the detection of fluorescent markers exploiting first-order DFB. This was made possible by placing the distributed feedback laser and the measuring site into two different parts of the device [194].

These examples show how NIL is making the production of $\mathrm{PhC}$ sensor easier and faster. NIL has already been adopted as a fabrication processes for Klarite ${ }^{\mathrm{TM}}$ Surface Enhancement Raman Spectroscopy (SERS) sensing platform commercialized by Renishaw [195]. In a publication dated 2013, the sensing platform was transferred from silicon to plastic platform by roll-to-roll and sheet-level NIL, 
achieving faster and cheaper mass production together with a eightfold sensitivity improvement to Benzenthiol compared to the silicon sensor [196]. In 2014, a similar roll-to-roll SERS detector allowed sensitivity to traces of ibuprofen $\left(10^{-4} \mathrm{M}\right)$. In the same work, a functionalized sensor coupled with a Young's interferometer waveguide and a flow cell reported sensitivity down to $1 \mathrm{ppm}$ of formaldehyde [197].

\section{Conclusions}

Since 1995, when it was just an embossing tool for polymer, the potential of nanoimprint lithography has attracted enormous attention from both the Academia and the Industry. As a result, the technology has evolved rapidly and its capabilities have escalated. Today nanoimprint and the soft lithographies derived from it allow imprinting one- to three-dimensional structures with feature sizes ranging from $5 \mathrm{~nm}$ to few hundreds of micrometers in a huge variety of materials, at cost and time scales unconceivable with any other lithographic technique.

In this chapter we introduced standard ultraviolet and thermal nanoimprint lithography and derivative soft lithography used for the fabrication of photonic structures in optoelectronic devices. We reviewed the imprinting of photonic structures in conducting and semiconducting polymer, metal, and metal oxide components of OLED, solar cells, lasers, and sensors, giving few examples of the extreme versatility of NIL for the control of light absorption, confinement, and propagation in optoelectronic devices.

\section{References}

1. L. Petti, M. Rippa, F. Capasso, G. Nenna, A. De Girolamo, M.G. Maglione, C. Minarini, Nanotechnology 315206, 24 (2013)

2. L. Hou, Q. Hou, Y. Mo, J. Peng, Y. Cao, Appl. Phys. Lett. 243504, 87 (2005)

3. G.-G. Zheng, F.-L. Xian, X.-Y. Li, Chin. Phys. Lett. 054213, 28 (2011)

4. A. Mihi, M.E. Calvo, J.A. Anta, H. Miguez, J. Phys. Chem. C 13, 112 (2008)

5. R. Betancur, P. Romero-Gomez, A. Martinez-Otero, X. Elias, M. Maymo, J. Martorell, Nat. Photon. 995, 7 (2013)

6. L. Frezza, M. Patrini, M. Liscidini, D. Comoretto, J. Phys. Chem. C 19939, 115 (2011)

7. G. Canazza, F. Scotognella, G. Lanzani, S. De Silvestri, M. Zavelani-Rossi, D. Comoretto, Laser Phys. Lett. 035804, 11 (2014)

8. S. Hu, Y. Zhao, K. Qin, S.T. Retterer, I.I. Kravchenko, S.M. Weiss, ACS Photon. 590, 1 (2014)

9. H. Ding, C. Liu, H. Gu, Y. Zhao, B. Wang, Z. Gu, ACS Photon. 121, 1 (2014)

10. H.S. Lim, J.-H. Lee, J.J. Walish, E.L. Thomas, ACS Nano 8933, 6 (2012)

11. Y. Xia, B. Gates, Z.Y. Li, Adv. Mater. 409, 13 (2001)

12. G. von Freymann, V. Kitaev, B.V. Lotsch, G.A. Ozin, Chem. Soc. Rev. 2528, 42 (2013)

13. S.Y. Chou, P.R. Krauss, P.J. Renstrom, Appl. Phys. Lett. 3114, 67 (1995) 
14. D. Morecroft, J.K.W. Yang, S. Schuster, K.K. Berggren, Q. Xia, W. Wu, R.S. Williams, J. Vac. Sci. Technol. B 2837, 27 (2009)

15. L.J. Guo, J. Phys. D Appl. Phys. R123, 37 (2004)

16. T. Eriksson, S. Yamada, P.V. Krishnan, S. Ramasamy, B. Heidari, Microelectron. Eng. 293, 88 (2011)

17. S.Y. Chou, P.R. Krauss, P.J. Renstrom, Science 85, 272 (1996)

18. M.D. Austin, H. Ge, W. Wu, M. Li, Z. Yu, D. Wasserman, S.A. Lyon, S.Y. Chou, Appl. Phys. Lett. 5299, 84 (2004)

19. G.-Y. Jung, E. Johnston-Halperin, W. Wu, Z. Yu, S.-Y. Wang, W.M. Tong, Z. Li, J.E. Green, B.A. Sheriff, A. Boukai, Y. Bunimovich, J.R. Heath, R.S. Williams, Nano Lett. 351, 6 (2006)

20. R. Ganesan, J. Dumond, M.S.M. Saifullah, S.H. Lim, H. Hussain, H.Y. Low, ACS Nano 1494, 6 (2012)

21. S. Takei, T. Ogawa, R. Deschner, C.G. Willson, Microelectron. Eng. 44, 116 (2014)

22. X. Sun, W. Chen, R. Zhou, W. Chen, J. Zhang, Rev. Sci. Instrum. 125002, 84 (2013)

23. J. Choi, K. Nordquist, A. Cherala, L. Casoose, K. Gehoski, W.J. Dauksher, S.V. Sreenivasan, D.J. Resnick, Microelectron. Eng. 633, 78-79 (2005)

24. S.M. Kim, J.H. Kang, W.I. Lee, Polym. Eng. Sci. 209, 51 (2011)

25. A. Jain, R.T. Bonnecaze, J. Appl. Phys. 234511, 113 (2013)

26. C. Masclaux, C. Gourgon, C. Perret, S. Labau, Microelectron. Eng. 2048, 88 (2011)

27. http://www.evgroup.com/en/products/lithography/nanoimprint_systems/. 5 November 2014

28. http://www.molecularimprints.com/. 5 November 2014

29. http://www.nanonex.com/. 5 November 2014

30. http://www.obducat.com/. 5 November 2014

31. http://www.set-sas.fr/en/cat424981-424981-NPS300.html. 5 November 2014

32. http://www.nilt.com/544/nanoimprint-lithography-(nil)-tools. 5 November 2014

33. https://www.suss.com/en/products-solutions/technologies/imprint-lithography.html. 5 November 2014

34. Y. Hirai, J. Photopolym. Sci. Technol. 551, 18 (2005)

35. L.J. Guo, Adv. Mater. 495, 19 (2007)

36. M. Elsayed, O.M. Merkel, Nanomedicine 349, 9 (2014)

37. C. Goh, K.M. Coakley, M.D. McGehee, Nano Lett. 1545, 5 (2005)

38. M.J. Hampton, J.L. Templeton, J.M. DeSimone, Langmuir 3012, 26 (2010)

39. K. Felmet, Y.-L. Loo, Y. Sun, Appl. Phys. Lett. 3316, 85 (2004)

40. S. Buzzi, F. Robin, V. Callegari, J.F. Löffler, Microelectron. Eng. 419, 85 (2008)

41. B. Radha, S.H. Lim, M.S.M. Saifullah, G.U. Kulkarni, Sci. Rep. 1078, 3 (2013)

42. M. Aryal, K. Trivedi, W. Hu, ACS Nano 3085, 3 (2009)

43. L. Jiang, X. Wang, L. Chi, Small 1309, 7 (2011)

44. Y. Xu, F. Zhang, X. Feng, Small 1338, 7 (2011)

45. H.-W. Li, W.T.S. Huck, Nano Lett. 1633, 4 (2004)

46. J. Kouba, M. Kubenz, A. Mai, G. Ropers, W. Eberhardt, B. Loechel, J. Phys. Conf. Ser. 34, 897 (2006). IOP Publishing

47. X.-Z. Chen, H.-Y. Li, Chin. Phys. Lett. 2830, 24 (2007)

48. G.H. Jeong, J.K. Park, K.K. Lee, J.H. Jang, C.H. Lee, H.B. Kang, C.W. Yang, S.J. Suh, Microelectron. Eng. 51, 87 (2010)

49. W. Zhou, Nanoimprint Lithography: An Enabling Process for Nanofabrication (Springer, Heidelberg, 2013), p. 33

50. S. Zankovych, T. Hoffmann, J. Seekamp, J.U. Bruch, C.M.S. Torres, Nanotechnology 91, $12(2001)$

51. L. Hongbo, D. Yucheng, Nanoimprint Lithography, Lithography (InTech, Rijeka, 2010)

52. D.-G. Choi, J.-H. Jeong, Y.-S. Sim, E.-S. Lee, W.-S. Kim, B.-S. Bae, Langmuir 9390, 21 (2005)

53. K. Hyewon, L. Jiyeon, P. Joonhyung, H.L. Hong, Nanotechnology 197, 17 (2006)

54. H. Tan, A. Gilbertson, S.Y. Chou, J. Vac. Sci. Technol. B 3926, 16 (1998) 
55. S.H. Ahn, L.J. Guo, ACS Nano 2304, 3 (2009)

56. J. John, Y. Tang, J.P. Rothstein, J.J. Watkins, K.R. Carter, Nanotechnology 505307, 24 (2013)

57. S. Ahn, J. Cha, H. Myung, S.-M. Kim, S. Kang, Appl. Phys. Lett. 213101, 89 (2006)

58. T.-C. Huang, J.-T. Wu, S.-Y. Yang, P.-H. Huang, S.-H. Chang, Microelectron. Eng. 615, $86(2009)$

59. S. Park, K. Choi, G. Kim, J. Lee, Microelectron. Eng. 604, 86 (2009)

60. X.D. Huang, L.-R. Bao, X. Cheng, L.J. Guo, S.W. Pang, A.F. Yee, J. Vac. Sci. Technol. B 2872, 20 (2002)

61. V. Reboud, A.Z. Khokhar, B. Sepulveda, D. Dudek, T. Kehoe, J. Cuffe, N. Kehagias, M. Lira-Cantu, N. Gadegaard, V. Grasso, V. Lambertini, C.M. Sotomayor Torres, Nanoscale 3495, 4 (2012)

62. K.G.A. Tavakkoli, M. Ranjbar, S.N. Piramanayagam, S.K. Wong, W.C. Poh, R. Sbiaa, T.C. Chong, Nanosci. Nanotechnol. Lett. 835, 4 (2012)

63. K.-S. Han, S.-H. Hong, K.-I. Kim, J.-Y. Cho, K.-W. Choi, H. Lee, Nanotechnology 045304, $24(2013)$

64. N. Kehagias, V. Reboud, G. Chansin, M. Zelsmann, C. Jeppesen, F. Reuther, C. Schuster, M. Kubenz, G. Gruetzner, C.M. Sotomayor Torres, J. Vac. Sci. Technol. B 3002, 24 (2006) 65. H. Park, H. Li, X. Cheng, J. Vac. Sci. Technol. B 2325, 25 (2007)

66. X.-M. Zhao, Y. Xia, G.M. Whitesides, Adv. Mater. 837, 8 (1996)

67. A. Kumar, G.M. Whitesides, Appl. Phys. Lett. 2002, 63 (1993)

68. T. Kaufmann, B.J. Ravoo, Polym. Chem. 371, 1 (2010)

69. C.-P. Chang, P.-C. Wang, Y.-Y. Nian, Y.-M. Liu, M.-D. Ger, J. Taiwan Inst. Chem. Eng. 2755, 45 (2014)

70. S.-T. Han, Y. Zhou, Z.-X. Xu, L.-B. Huang, X.-B. Yang, V.A.L. Roy, Adv. Mater. 3556, $24(2012)$

71. C.-J. Pan, H. Qin, Y.-D. Nie, H.-Y. Ding, Colloids Surf. B 18, 104 (2013)

72. O.A. Nafday, T.W. Lowry, S. Lenhert, Small 1021, 8 (2012)

73. S.A. Lange, V. Benes, D.P. Kern, J.K.H. Hörber, A. Bernard, Anal. Chem. 1641, 76 (2004)

74. J. Voskuhl, J. Brinkmann, P. Jonkheijm, Curr. Opin. Chem. Biol. 1, 18 (2014)

75. T. Granlund, T. Nyberg, L. Stolz Roman, M. Svensson, O. Inganäs, Adv. Mater. 269, $12(2000)$

76. J. Yao, X. Yan, G. Lu, K. Zhang, X. Chen, L. Jiang, B. Yang, Adv. Mater. 81, 16 (2004)

77. E. Kim, Y. Xia, G.M. Whitesides, Nature 581, 376 (1995)

78. E. Kim, Y. Xia, G.M. Whitesides, J. Am. Chem. Soc. 5722, 118 (1996)

79. Y. Xia, E. Kim, G.M. Whitesides, Chem. Mater. 1558, 8 (1996)

80. E. King, Y. Xia, X.-M. Zhao, G.M. Whitesides, Adv. Mater. 651, 9 (1997)

81. N.E. Voicu, S. Ludwigs, E.J.W. Crossland, P. Andrew, U. Steiner, Adv. Mater. 757, 19 (2007)

82. F.C. Krebs, Sol. Energy Mater. Sol. Cells 465, 93 (2009)

83. F.C. Krebs, J. Fyenbo, M. Jorgensen, J. Mater. Chem. 8994, 20 (2010)

84. D.-H. Ko, J.R. Tumbleston, A. Gadisa, M. Aryal, Y. Liu, R. Lopez, E.T. Samulski, J. Mater. Chem. 16293, 21 (2011)

85. D. Duché, L. Escoubas, J.-J. Simon, P. Torchio, W. Vervisch, F. Flory, Appl. Phys. Lett. 193310, 92 (2008)

86. L. Yingchi, K. Christoph, G. Abay, A. Mukti, M. Sorin, T.S. Edward, L. Rene, J. Phys. D Appl. Phys. 024008, 46 (2013)

87. J.-Y. Chen, M.-H. Yu, C.-Y. Chang, Y.-H. Chao, K.W. Sun, C.-S. Hsu, ACS Appl. Mater. Interfaces 6164, 6 (2014)

88. D.H. Wang, J. Seifter, J.H. Park, D.-G. Choi, A.J. Heeger, Adv. Energy Mater. 1319, 1319-1322 (2012)

89. T.H. Reilly, J. van de Lagemaat, R.C. Tenent, A.J. Morfa, K.L. Rowlen, Appl. Phys. Lett. 92, 013504 (2008) 
90. N.C. Lindquist, W.A. Luhman, S.-H. Oh, R.J. Holmes, Appl. Phys. Lett. 93, 123308 (2008)

91. J. You, X. Li, F.-X. Xie, W.E.I. Sha, J.H.W. Kwong, G. Li, W.C.H. Choy, Y. Yang, Adv. Energy Mater. 1203, 2 (2012)

92. M.-G. Kang, H.J. Park, A. Se Hyun, T. Xu, L.J. Guo, IEEE J. Sel. Top. Quantum Electron. 1807(16) (2010)

93. S.Y. Chou, W. Ding, Opt. Exp. A60, 21 (2013)

94. M.-G. Kang, T. Xu, H.J. Park, X. Luo, L.J. Guo, Adv. Mater. 4378, 22 (2010)

95. H.J. Park, T. Xu, J.Y. Lee, A. Ledbetter, L.J. Guo, ACS Nano 7055, 5 (2011)

96. W. Ding, S.Y. Chou, in Photovoltaic Specialist Conference (PVSC), 2014 I.E. 40th 2014, p. 2804

97. W.-Y. Chou, J. Chang, C.-T. Yen, F.-C. Tang, H.-L. Cheng, M.-H. Chang, S. Lien-Chung Hsu, J.-S. Chen, Y.-C. Lee, Appl. Phys. Lett. 183108, 99 (2011)

98. O.P. Dimitriev, D.A. Grinko, Y.V. Noskov, N.A. Ogurtsov, A.A. Pud, Synth. Met. 2237, 159 (2009)

99. U. Lang, P. Rust, B. Schoberle, J. Dual, Microelectron. Eng. 330, 86 (2009)

100. J.B. Emah, R.J. Curry, S.R.P. Silva, Appl. Phys. Lett. 103301, 93 (2008)

101. X. Zhu, W.C.H. Choy, F. Xie, C. Duan, C. Wang, W. He, F. Huang, Y. Cao, Sol. Energy Mater. Sol. Cells 327, 99 (2012)

102. J.-H. Choi, H.-J. Choi, J.-H. Shin, H.-P. Kim, J. Jang, H. Lee, Org. Electron. 3180, 14 (2013)

103. Y. Yang, K. Lee, K. Mielczarek, W. Hu, A. Zakhidov, Nanotechnology 485301, 22 (2011)

104. S.-I. Na, S.-S. Kim, S.-S. Kwon, J. Jo, J. Kim, T. Lee, D.-Y. Kim, Appl. Phys. Lett. 173509 , 91 (2007)

105. D.-H. Ko, J.R. Tumbleston, W. Schenck, R. Lopez, E.T. Samulski, J. Phys. Chem. C 4247, 115 (2011)

106. X.H. Li, W.E.I. Sha, W.C.H. Choy, D.D.S. Fung, F.X. Xie, J. Phys. Chem. C 7200, 116 (2012)

107. L. Stolz Roman, O. Inganäs, T. Granlund, T. Nyberg, M. Svensson, M.R. Andersson, J.C. Hummelen, Adv. Mater. 189, 12 (2000)

108. M. Niggemann, M. Glatthaar, A. Gombert, A. Hinsch, V. Wittwer, Thin Solid Films 619, 451-452 (2004)

109. Y.-S. Cheng, C. Gau, Sol. Energy Mater. Sol. Cells 566, 120 (2014). Part B

110. J.R. Tumbleston, A. Gadisa, Y. Liu, B.A. Collins, E.T. Samulski, R. Lopez, H. Ade, ACS Appl. Mater. Interfaces 8225, 5 (2013)

111. D. Cheyns, K. Vasseur, C. Rolin, J. Genoe, J. Poortmans, P. Heremans, Nanotechnology 424016, 19 (2008)

112. O. Wiedenmann, A. Abdellah, G. Scarpa, P. Lugli, J. Phys. Conf. Ser. 012115, 193 (2009)

113. Y. Yang, M. Aryal, K. Mielczarek, W. Hu, A. Zakhidov, J. Vac. Sci. Technol. B C6M104, 28 (2010)

114. D.-G. Choi, K.-J. Lee, J.-H. Jeong, D. Hwan Wang, O. Ok Park, J. Hyeok Park, Sol. Energy Mater. Sol. Cells 1, 109 (2013)

115. Y. Yang, K. Mielczarek, A. Zakhidov, W. Hu, ACS Appl. Mater. Interfaces 19282, 6 (2014)

116. D. Chen, W. Zhao, T.P. Russell, ACS Nano 1479, 6 (2012)

117. M. Aryal, F. Buyukserin, K. Mielczarek, X.-M. Zhao, J. Gao, A. Zakhidov, W. Hu, J. Vac. Sci. Technol. B 2562, 26 (2008)

118. X. He, F. Gao, G. Tu, D. Hasko, S. Hüttner, U. Steiner, N.C. Greenham, R.H. Friend, W.T.S. Huck, Nano Lett. 1302, 10 (2010)

119. X. He, F. Gao, G. Tu, D.G. Hasko, S. Hüttner, N.C. Greenham, U. Steiner, R.H. Friend, W.T.S. Huck, Adv. Funct. Mater. 139, 21 (2011)

120. W. Wiedemann, L. Sims, A. Abdellah, A. Exner, R. Meier, K.P. Musselman, J.L. MacManusDriscoll, P. Müller-Buschbaum, G. Scarpa, P. Lugli, L. Schmidt-Mende, Appl. Phys. Lett. 263109, 96 (2010)

121. M. Zhou, M. Aryal, K. Mielczarek, A. Zakhidov, W. Hu, J. Vac. Sci. Technol. B C6M63, 28 (2010) 
122. J.S. Kim, Y. Park, D.Y. Lee, J.H. Lee, J.H. Park, J.K. Kim, K. Cho, Adv. Funct. Mater. 540, 20 (2010)

123. Y. Yang, K. Mielczarek, M. Aryal, A. Zakhidov, W. Hu, Nanoscale 7576, 6 (2014)

124. W. Zeng, K.S.L. Chong, H.Y. Low, E.L. Williams, T.L. Tam, A. Sellinger, Thin Solid Films 6833, 517 (2009)

125. K.M. Coakley, B.S. Srinivasan, J.M. Ziebarth, C. Goh, Y. Liu, M.D. McGehee, Adv. Funct. Mater. 1927, 15 (2005)

126. Z. Hu, G. Baralia, V. Bayot, J.-F. Gohy, A.M. Jonas, Nano Lett. 1738, 5 (2005)

127. S.A. Schmid, K.H. Yim, M.H. Chang, Z. Zheng, W.T.S. Huck, R.H. Friend, J.S. Kim, L.M. Herz, Phys. Rev. B 115338, 77 (2008)

128. H. Hlaing, X. Lu, T. Hofmann, K.G. Yager, C.T. Black, B.M. Ocko, ACS Nano 7532, 5 (2011)

129. Z. Hu, A.M. Jonas, Soft Matter 21, 6 (2010)

130. G. Ding, Y. Wu, Y. Weng, W. Zhang, Z. Hu, Macromolecules 8638, 46 (2013)

131. J.H. Lee, D.W. Kim, H. Jang, J.K. Choi, J. Geng, J.W. Jung, S.C. Yoon, H.-T. Jung, Small 2139, 5 (2009)

132. B.-C. Chen, Y.-S. Cheng, C. Gau, Y.-C. Lee, Thin Solid Films 384, 564 (2014)

133. S.-I. Na, S.-S. Kim, J. Jo, S.-H. Oh, J. Kim, D.-Y. Kim, Adv. Funct. Mater. 3956, 18 (2008)

134. J.Y. Park, N.R. Hendricks, K.R. Carter, Langmuir 11251, 27 (2011)

135. T. Kohei, T. Kazuhiro, I. Manabu, F. Honoka, N. Naoki, K. Hiroaki, H. Yoshihiko, Jpn. J. Appl. Phys. 06GJ03, 52 (2013)

136. A. David, H. Benisty, C. Weisbuch, Rep. Prog. Phys. 126501, 75 (2012)

137. Q.-C. Hsu, J.-J. Hsiao, T.-L. Ho, C.-D. Wu, Microelectron. Eng. 178, 91 (2012)

138. C.-J. Yang, S.-H. Liu, H.-H. Hsieh, C.-C. Liu, T.-Y. Cho, C.-C. Wu, Appl. Phys. Lett. 253508, 91 (2007)

139. J.P. Yang, Q.Y. Bao, Z.Q. Xu, Y.Q. Li, J.X. Tang, S. Shen, Appl. Phys. Lett. 223303, 97 (2010)

140. Wei, M.-K.; Su, I.-L., Opt. Express 5777, 12, (2004)

141. D. Suh, H.H. Lee, J. Vac. Sci. Technol. B 1123, 22 (2004)

142. K. Ishihara, M. Fujita, I. Matsubara, T. Asano, S. Noda, H. Ohata, A. Hirasawa, H. Nakada, N. Shimoji, Appl. Phys. Lett. 111114, 90 (2007)

143. K. Trivedi, U.S. Bhansali, B. Gnade, W. Hu, Nanotechnology 405204, 20 (2009)

144. A.O. Altun, S. Jeon, J. Shim, J.-H. Jeong, D.-G. Choi, K.-D. Kim, J.-H. Choi, S.-W. Lee, E.-S. Lee, H.-D. Park, J.R. Youn, J.-J. Kim, Y.-H. Lee, J.-W. Kang, Org. Electron. 711, 11 (2010)

145. Y.D. Kim, K.-H. Han, S.-J. Park, J.-B. Kim, J.-H. Shin, J.J. Kim, H. Lee, Opt. Lett. 5901, 39 (2014)

146. P. Melpignano, V. Biondo, S. Sinesi, M.T. Gale, S. Westenhöfer, M. Murgia, S. Caria, R. Zamboni, Appl. Phys. Lett. 153514, 88 (2006)

147. S. Jeon, J.-W. Kang, H.-D. Park, J.-J. Kim, J.R. Youn, J. Shim, J.-H. Jeong, D.-G. Choi, K.-D. Kim, A.O. Altun, S.-H. Kim, Y.-H. Lee, Appl. Phys. Lett. 223307, 92 (2008)

148. Y. Luo, C. Wang, L. Wang, Y. Ding, L. Li, B. Wei, J. Zhang, ACS Appl. Mater. Interfaces 10213, 6 (2014)

149. J. Choi, D. Kim, P.J. Yoo, H.H. Lee, Adv. Mater. 166, 17 (2005)

150. J.R. Lawrence, P. Andrew, W.L. Barnes, M. Buck, G.A. Turnbull, I.D.W. Samuel, Appl. Phys. Lett. 1955, 81 (2002)

151. M. Tamborra, M. Striccoli, M.L. Curri, J.A. Alducin, D. Mecerreyes, J.A. Pomposo, N. Kehagias, V. Reboud, C.M. Sotomayor Torres, A. Agostiano, Small 822, 3 (2007)

152. V. Reboud, N. Kehagias, C.M. Sotomayor Torres, M. Zelsmann, M. Striccoli, M.L. Curri, A. Agostiano, M. Tamborra, M. Fink, F. Reuther, G. Gruetzner, Appl. Phys. Lett. 011115, 90 (2007)

153. X. Li, G. Yang, J. Chen, R. Zhang, W. Zhou, Y. Liu, J. Zhang, Q. Wang, Surf. Rev. Lett. 367, 16 (2009)

154. C. Piliego, M. Mazzeo, B. Cortese, R. Cingolani, G. Gigli, Org. Electron. 401, 9 (2008) 
155. J.M. Ziebarth, A.K. Saafir, S. Fan, M.D. McGehee, Adv. Funct. Mater. 451, 14 (2004)

156. L. Zhou, Q.-D. Ou, J.-D. Chen, S. Shen, J.-X. Tang, Y.-Q. Li, S.-T. Lee, Sci. Rep. 4040, 4 (2014)

157. L. Zhou, X. Jiang, Y. Li, A. Shi, J. Chen, Q. Ou, H. Liu, J. Tang, ACS Appl. Mater. Interfaces 18139, 6 (2014)

158. Q.-D. Ou, L. Zhou, Y.-Q. Li, S. Shen, J.-D. Chen, C. Li, Q.-K. Wang, S.-T. Lee, J.-X. Tang, Adv. Funct. Mater. 24, 7249-7256 (2014)

159. H. Kogelnik, C.V. Shank, Appl. Phys. Lett. 152, 18 (1971)

160. M. Berggren, A. Dodabalapur, R.E. Slusher, A. Timko, O. Nalamasu, Appl. Phys. Lett. 410, $72(1998)$

161. G.A. Turnbull, P. Andrew, M.J. Jory, W.L. Barnes, I.D.W. Samuel, Phys. Rev. B 125122, 64 (2001)

162. G. Tsiminis, Y. Wang, A.L. Kanibolotsky, A.R. Inigo, P.J. Skabara, I.D.W. Samuel, G.A. Turnbull, Adv. Mater. 2826, 25 (2013)

163. E.R. Martins, Y. Wang, A.L. Kanibolotsky, P.J. Skabara, G.A. Turnbull, I.D.W. Samuel, Adv. Opt. Mater. 563, 1 (2013)

164. Y. Wang, G. Tsiminis, A.L. Kanibolotsky, P.J. Skabara, I.D.W. Samuel, G.A. Turnbull, Opt. Exp. 14362, 21 (2013)

165. C. Vannahme, F. Maier-Flaig, U. Lemmer, A. Kristensen, Lab Chip 2675, 13 (2013)

166. X. Liu, S. Prinz, H. Besser, W. Pfleging, M. Wissmann, C. Vannahme, M. Guttmann, T. Mappes, S. Koeber, C. Koos, U. Lemmer, Faraday Discuss 174, 153-164 (2014)

167. M. Punke, T. Woggon, M. Stroisch, B. Ebenhoch, U. Geyer, C. Karnutsch, M. Gerken, U. Lemmer, M. Bruendel, J. Wang, T. Weimann, Proc. SPIE 6659, 665909 (2007)

168. Y. Chen, Z. Li, Z. Zhang, D. Psaltis, A. Scherer, Appl. Phys. Lett. 051109, 91 (2007)

169. A. Retolaza, A. Juarros, D. Otaduy, S. Merino, V. Navarro-Fuster, M.G. Ramírez, P.G. Boj, J.A. Quintana, J.M. Villalvilla, M.A. Díaz-García, Microelectron. Eng. 52, 114 (2014)

170. E.B. Namdas, M. Tong, P. Ledochowitsch, S.R. Mednick, J.D. Yuen, D. Moses, A.J. Heeger, Adv. Mater. 799, 21 (2009)

171. C. Ge, M. Lu, X. Jian, Y. Tan, B.T. Cunningham, Opt. Exp. 12980, 18 (2010)

172. B.C. Mads, B. Thomas, L.C.S. Cameron, R.P. Sidsel, M.J. Mette, K. Anders, J. Micromech. Microeng. 115025, 20 (2010)

173. J.P. Dowling, M. Scalora, M.J. Bloemer, C.M. Bowden, J. Appl. Phys. 1896, 75 (1994)

174. V. Reboud, J. Romero-Vivas, P. Lovera, N. Kehagias, T. Kehoe, G. Redmond, C.M. Sotomayor Torres, Appl. Phys. Lett. 073101, 102 (2013)

175. V. Reboud, N. Kehagias, P. Lovera, M. Zelsmann, C. Schuster, F. Reuther, G. Gruetzner, G. Redmond, C.M.S. Torres, Jpn. J. Appl. Phys. 5139, 47 (2008)

176. D. Pisignano, L. Persano, P. Visconti, R. Cingolani, G. Gigli, G. Barbarella, L. Favaretto, Appl. Phys. Lett. 2545, 83 (2003)

177. E. Mele, F. Di Benedetto, L. Persano, R. Cingolani, D. Pisignano, Nano Lett. 1915, 5 (2005)

178. E. Mele, A. Camposeo, R. Stabile, P. Del Carro, F. Di Benedetto, L. Persano, R. Cingolani, D. Pisignano, Appl. Phys. Lett. 131109, 89 (2006)

179. L. Persano, A. Camposeo, P.D. Carro, V. Fasano, M. Moffa, R. Manco, S. D’Agostino, D. Pisignano, Adv. Mater. 6660, 26 (2014)

180. M. Salerno, G. Gigli, M. Zavelani-Rossi, S. Perissinotto, G. Lanzani, Appl. Phys. Lett. 111110, 90 (2007)

181. J.R. Lawrence, G.A. Turnbull, I.D.W. Samuel, Appl. Phys. Lett. 4023, 82 (2003)

182. F. Bernal Arango, M.B. Christiansen, M. Gersborg-Hansen, A. Kristensen, Appl. Phys. Lett. 223503, 91 (2007)

183. M. Ben-Moshe, V.L. Alexeev, S.A. Asher, Anal. Chem. 5149, 78 (2006)

184. X. Xu, A.V. Goponenko, S.A. Asher, J. Am. Chem. Soc. 3113, 130 (2008)

185. P.Y. Li, L. Bo, J. Gerstenmaier, B.T. Cunningham, in Sensors, 2003. Proceedings of IEEE 2003, vol. 1, p. 310

186. I.D. Block, L.L. Chan, B.T. Cunningham, Sens. Actuators B 187, 120 (2006) 
187. T. Endo, S. Ozawa, N. Okuda, Y. Yanagida, S. Tanaka, T. Hatsuzawa, Sens. Actuators B 269, 148 (2010)

188. F. Morhard, J. Pipper, R. Dahint, M. Grunze, Sens. Actuators B 232, 70 (2000)

189. A. Rose, Z. Zhu, C.F. Madigan, T.M. Swager, V. Bulovic, Nature 876, 434 (2005)

190. A.M. Haughey, B. Guilhabert, A.L. Kanibolotsky, P.J. Skabara, G.A. Burley, M.D. Dawson, N. Laurand, Sens. Actuators B 132, 185 (2013)

191. M. Lu, S.S. Choi, C.J. Wagner, J.G. Eden, B.T. Cunningham, Appl. Phys. Lett. 261502, 92 (2008)

192. M. Lu, S.S. Choi, U. Irfan, B.T. Cunningham, Appl. Phys. Lett. 111113, 93 (2008)

193. M.B. Christiansen, J.M. Lopacinska, M.H. Jakobsen, N.A. Mortensen, M. Dufva, A. Kristensen, Opt. Exp. 2722, 17 (2009)

194. C. Vannahme, S. Klinkhammer, U. Lemmer, T. Mappes, Opt. Express 8179, 19 (2011)

195. http://www.renishawdiagnostics.com/en/eu-project-delivers-new-possibilities-for-sers-sen sors--24329. Retrieved on 15 November 2014

196. S.Z. Oo, R.Y. Chen, S. Siitonen, V. Kontturi, D.A. Eustace, J. Tuominen, S. Aikio, M.D.B. Charlton, Opt. Exp. 18484, 21 (2013)

197. P. Karioja, J. Hiltunen, S. Aikio, T. Alajoki, J. Tuominen, M. Hiltunen, S. Siitonen, V. Kontturi, K. Böhlen, R. Hauser, in SPIE Photonics Europe, International Society for Optics and Photonics: 2014, p. 91410D 